\title{
INTENSIFICAÇÃO DO VENTO DEVIDO A INFLUÊNCIAS DO RELEVO: EVI- DÊNCIAS A PARTIR DE MODELOS NUMÉRICOS E MEDIDAS IN SITU
}

\author{
Arcilan T. Assireu ${ }^{1, *}$, Cláudio C. Pellegrini ${ }^{2}$, Felipe M. Pimenta ${ }^{3}$ \\ ${ }^{1}$ UNIFEI, Itajubá, MG \\ ${ }^{2}$ UFSJ, São João del-Rei, MG \\ ${ }^{3}$ UFRN, Natal, RN \\ *assireu@gmail.com
}

\section{RESUMO}

O efeito de canalização do vento promovido por montanhas alinhadas a um vale, ocupado por um grande reservatório hidrelétrico, é estudado a partir de modelagem numérica, dados in situ de vento e modelo digital de terreno. Os resultados indicam que, como o reservatório foi construído a partir do represamento de rios que fluíam entre montanhas, a resultante inundação do respectivo vale resultou em canalização do vento.

\begin{abstract}
In order to evaluate the influence of topography to wind flow on a reservoir where the mountains tend to channel the winds, we employ numerical model, topographic relief from the Shuttle Radar Topographic Mapper and wind data. The results indicate that mountains tend to channel the winds, providing the convergence of low level jets associated with easterly winds.
\end{abstract}

\section{INTRODUÇÃO}

Os reservatórios de água destinados ao abastecimento de cidades ou de usinas hidroelétricas construídos em regiões de planalto possuem, normalmente, forma alongada com o relevo mais elevado disposto ao longo de seu eixo principal. Isto pode introduzir regiões de convergência para o vento sobre o lago, criando condições orográficas locais favoráveis à intensificação do vento e à sua maior persistência em direção (MASON, 1986; FINNIGAN et al., 1990; BULLARD et al., 2000). Ambos os efeitos são importantes uma vez que se considere a possibilidade de instalação de turbinas eólicas nestes reservatórios. Especificamente, a redução da variabilidade na direção facilita a escolha dos locais mais adequados para a instalação das turbinas ao longo do lago. A circulação sobre o lago, entretanto, é fortemente dependente dos sistemas atmosféricos de larga escala (WEIGEL e ROTACH, 2004; BITENCOUT et al., 2009).

Neste trabalho, o uso conjugado de modelagem numérica, dados medidos e modelo digital de relevo é empregado com o objetivo de verificar se os resultados levantados na literatura acerca da influência do relevo para o campo de vento se verifica em condições típicas de reservatórios em região de planalto. 


\section{MATERIAIS E MÉTODOS}

Dados de vento coletados por uma boia SIMA (Sistema Integrado de Monitoramento Ambiental) para o reservatório de Itumbiara (GO) foram cotejados com mapas digitais de elevação (MDE) para a região a fim de avaliar a influência da topografia no regime de ventos. Neste trabalho, foram utilizados 02 anos de dados de vento medidos por uma boia ancorada no reservatório na posição indicada na Figura 1.

As simulações foram realizadas com a versão 3.2 do WRF. Apenas um dia do ano de 2010 foi simulado neste estudo preliminar. A simulação foi iniciada às 18:00 do dia 30/05/2010 e encerrada às 00:00 do dia 01/06/2010, sendo as primeiras seis horas descartadas da análise como tempo de ajuste do modelo. $\mathrm{O}$ dia foi escolhido dentre os períodos nos quais se dispõe de medidas anemométricas obtidas no local para posterior comparação. Outras simulações estão sendo realizadas para avaliar o desempenho do WRF usando diferentes ajustes e comparando os resultados com todo o período observado de dados. O terreno foi representado através dos dados do USGS, com resolução de $0,5^{\prime}$. As simulações foram inicializadas com dados FNL de análise do modelo global GFS do NCEP (resolução de $1^{\circ}$ e 6 horas) também utilizados como condição de contorno ao longo da integração. Escolheu-se uma configuração de três domínios aninhados e centralizados em 18⒉ $21^{\prime} 43^{\prime \prime} \mathrm{S}, 48^{\circ} 59^{\prime 2} 29^{\prime \prime} \mathrm{W}$, com resoluções horizontais de 1 , 3 e $9 \mathrm{~km}$, todos com142x 142 pontos de grade. As parametrizações físicas usadas foram: esquema RRTM para a radiação de onda longa e Dudhia para a de onda curta, Single-Moment 6-class para a microfísica, Yonsei University para a Camada Limite Planetária, Monin-Obukhov para a camada superficial, nenhum para as nuvens cúmulos e Unified Noah como modelo de solo-superfície.

\section{RESULTADOS E DISCUSSÃO}

O MDE para Itumbiara (Fig. 1) permite verificar que as montanhas no entorno do reservatório se posicionam de forma a gerar um grande túnel ou canal com o reservatório ao centro. $\mathrm{O}$ efeito de canalização de vento fica evidente a partir da rosa dos ventos para este reservatório que indica a predominância de ventos de leste. Isto coincide com a direção do fetch principal do reservatório. Ventos do quadrante leste ocorreram em mais do que $60 \%$ do tempo. Como os ventos sinóticos, nesta região, são paralelos ao canal formado pelas montanhas, a topografia local tem um efeito de afunilamento, com potencial para modificar a direção e intensidade do vento, fenômeno conhecido como speed-up (BULLARD et al., 2000) em um processo similar ao identificado por WHITEMAN e DORAN (1993) para o Vale do Tennesse. A partir da curva de persistência (não mostrada) contatou-se que ventos com intensidade $>5 \mathrm{~m} / \mathrm{s}$ ocorrem em torno de $70 \%$ do tempo.

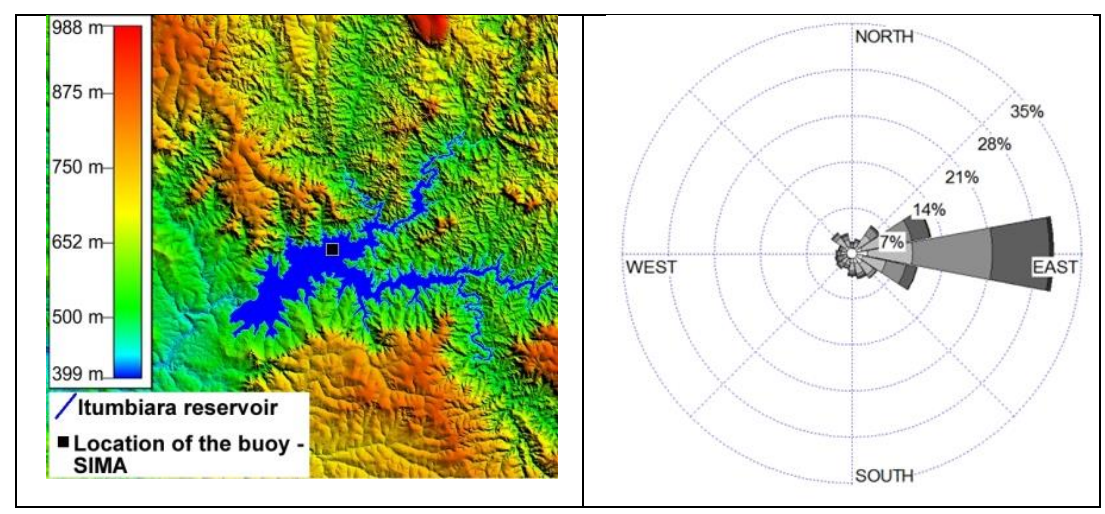

Figura 1. (a) Topografia e (b) rosa dos ventos. 
Os resultados do WRF corroboram os resultados anteriores. A Figura 2 mostra os campos simulados de vento horizontal às alturas de $30 \mathrm{~m}$ acima da superfície, onde percebe-se a "ilha de vento" em amarelo na parte central da Figura 2.

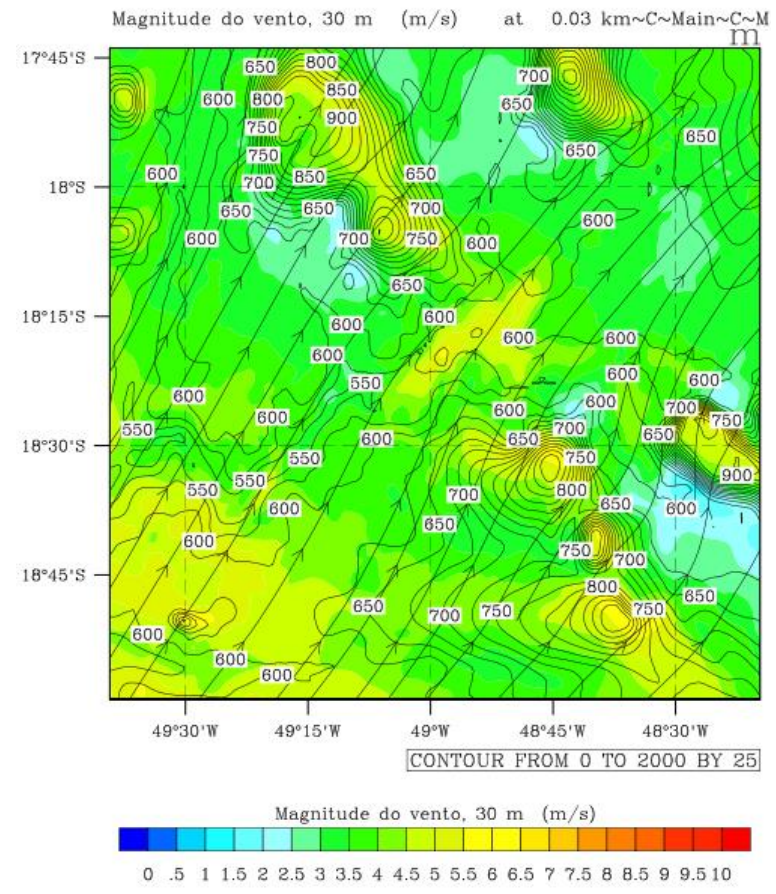

Figura 2. Simulação do vento a partir do WRFa $30 \mathrm{~m}$ do solo.

\section{CONCLUSÕES}

O uso conjunto de dados, modelo digital de elevação e simulação numérica permitiu constatar a influência do relevo sobre o vento na região do reservatório de Itumbiara (GO). Os resultados permitem inferir que o vento de larga escala, associado com sistemas sinóticos, convergem entre as montanhas e sofrem intensificação. O efeito de diferentes ajustes no modelo de mesoescala utilizado não foi realizado e se encontra presentemente em andamento.

\section{AGRADECIMENTOS}

À FAPEMIG e ao CNPq pelo apoio.

\section{REFERÊNCIAS}

BULLARD, J. E.; WIGGS, G.F.S.; NAHS, D. J. Experimental study of wind directional variability in the vicinity of a model valley. Geomorphology, 35, 127-143, 2000.

WHITEMAN, C. D.; DORAN, J.C. The relationship between overlying synoptic-scale flows and winds within a valley. Journal of Applied Meteorology, 32, 1669-1682, 1993. 